\title{
Cr (VI) Removal from Aqueous Solution Using Starch and Sodium Carboxymethyl Cellulose-Coated Fe and Fe /Ni Nanoparticles
}

\author{
Jiale Wang ${ }^{1}$, Bin Ji1 ${ }^{1,2,3}$, Yaorong Shu ${ }^{1}$, Wei Chen ${ }^{1 *}$, Lin Zhu ${ }^{1}$, Fengting Chen ${ }^{1}$ \\ ${ }^{1}$ School of Urban Construction, Wuhan University of Science and Technology, Wuhan 430065, China \\ ${ }^{2}$ Hubei Key Laboratory for Efficient Utilization and Agglomeration of Metallurgic Mineral Resources, \\ Wuhan University of Science and Technology, Wuhan, 430081, China \\ ${ }^{3}$ Hubei Key Laboratory of Regional Development and Environmental Response, Hubei University, \\ Wuhan, 430062, China
}

Received: 27 November 2017

Accepted: 23 January 2018

\begin{abstract}
Starch and sodium carboxymethyl cellulose-coated $\mathrm{Fe}$ and $\mathrm{Fe} / \mathrm{Ni}$ nanoparticles were synthesized and their $\mathrm{Cr}$ (VI) removal capabilities were evaluated and compared. We found that starch and sodium carboxymethyl cellulose-coated nanoscale zero-valent iron-nickel (SS-nZVI-Ni) showed the better $\mathrm{Cr}$ (VI) removal performance. The effect of acidic conditions on $\mathrm{Cr}(\mathrm{VI})$ removal by SS-Nzvi-Ni revealed that the $\mathrm{Cr}$ (VI) removal efficiency by SS-nZVI-Ni reached the maximum of $95.70 \%$ at $\mathrm{pH}=2$. The effect of different initial $\mathrm{Cr}$ (VI) concentrations showed that SS-nZVI-Ni performed well at a high $\mathrm{Cr}(\mathrm{VI})$ concentration. Langmuir-Hinshelwood first-order kinetic model could describe the reduction process well. SEM images revealed that SS-nZVI-Ni had a large surface area, which discarded the problem of aggregation. XRD and XPS analysis of SS-nZVI-Ni showed that SS-nZVI-Ni and Cr (III) formed an alloy on the surface of SS-nZVI-Ni after the reaction. The study provides an option for practical application of SS-nZVI-Ni in Cr (VI) removal.
\end{abstract}

Keywords: nanoscale zero-valent iron, sodium carboxymethyl cellulose, starch, Cr (VI) removal, first-order kinetic model

\section{Introduction}

Chromium (VI) is one of major industrial heavy metal contaminants that exists widely on the surface of the soil and in groundwater [1]. Moreover, chromium (VI), due to its high toxicity, could cause a series of problems for humans and animals. Chromium (VI) enters human

*e-mail: weichenwust@126.com body through skin contact or mist, which may lead to irritation in the upper respiratory tract, inflammation in the nose, injury in the nasal septum, and cancer in respiratory tract [2]. Many methods such as electrolytic reduction [3], chemical reduction [4], membrane filtration [5], and adsorption [6] have been applied to treat $\mathrm{Cr}(\mathrm{VI})$ containing wastewater. It has been proven that adsorption and chemical reduction are more efficient for $\mathrm{Cr}(\mathrm{VI})$ removal due to their high removal rate, simple production process, and low cost. 
In the last two decades, nanoscale zero-valent iron (nZVI) has been widely used to tackle polluted water $[7,8]$. Due to the larger reactive surface area and faster reaction rate, nZVI is considered more efficient than iron. Nevertheless, the large surface area can lead to agglomeration of the particles and be more easily oxidized in storage [9]. Researches have proven that nZVI, once being stabilized or supported, would decrease the phenomenon of agglomeration and oxidized in storage. Since then, some researchers have reported that nZVI was loading with extracts such as biochar [10], green tea4, and grape seed [11]. The advantage of extracts is that it improves the stability of nZVI. But its disadvantage is also prominent. In the processing procedure of extracts, $\mathrm{HCl}$ was used extensively, which caused secondary pollution. It remains waiting further research and improvement.

It has been reported that clay [12], starch [13], sodium carboxymethyl cellulose [14], and pectin [15] are good modifiers for nZVI. There is no denying that these modifiers can make a positive promotion to nZVI. In recent years, some researchers have reported the removal of chromium by using nZVI or modified nZVI [16]. But few people have focused on nZVI modification by two modifiers. Therefore, the combination of two analogous structures and organic properties applied to modify nZVI is worth researching.

In recent years, researchers have found a novel method of modifying nZVI by loading another metal (Ni [17] for example) on the surface of nZVI, shaping nano bimetal. The addition of another metal to nZVI can accelerate the corrosion of nZVI during the reaction [18]. On the contrary, the rate of another metal loaded on the surface of nZVI could cause positive or negative effects during reaction [18]. And there is still lack research modifying nZVI by combination of metal loading and organics such as starch or pectin.

In this paper, multiple modifiers were untied to optimize nZVI. And these multiple modifiers' performance on chromium (VI) removal in wastewater would be investigated. Modified nZVI with high removal efficiency would be made.

\section{Materials and Methods}

\section{Materials and Chemicals}

Ferrous sulfate heptahydrate $\left(\mathrm{FeSO}_{4} \cdot 7 \mathrm{H}_{2} \mathrm{O}\right)$ and Potassium dichromate $\left(\mathrm{K}_{2} \mathrm{Cr}_{2} \mathrm{O}_{7}\right)$ were purchased from Tianjin Fuchen Chemical Reagents Factory; sodium carboxymethyl cellulose was purchased from Sinipharm Chemical Reagent Co., Ltd.; Starch soluble and Nickel chloride hexahydrate were purchased from Shanghai Lingfeng Chemical Reagent Co., Ltd.

\section{Preparation of nZVI and Modified nZVI}

NZVI was prepared by liquid phase reaction. In a typical redox reaction, $0.3 \mathrm{M} \mathrm{NaBH}_{4}$ (freshly prepared) aqueous solution was subtly added dropwise into $0.5 \mathrm{M}$ $\mathrm{FeSO}_{4}$ aqueous solution with magnetic stirring apparatus mixing. The whole reaction process was protected under $\mathrm{N}_{2}$. The mixed suspension was filtered and watered by ethanol one time and ultra-pure water three times. Then nZVI was dried at $100^{\circ} \mathrm{C}$ in a vacuum oven for half an hour. The reaction equation is:

$$
\mathrm{Fe}^{2+}+\mathrm{BH}_{4}^{-}+2 \mathrm{H}_{2} \mathrm{O}=\mathrm{Fe}^{0}+\mathrm{BO}_{2}^{-}+2 \mathrm{H}^{+}+3 \mathrm{H}_{2}
$$

Then dried nZVI was added into $0.3 \mathrm{M} \mathrm{NiCl}$ aqueous solution with a magnetic stirring apparatus mixing 20 min under $\mathrm{N}_{2}$ protection. The reaction equation is:

$$
\mathrm{Fe}^{0}+\mathrm{Ni}^{2+}=\mathrm{Ni}+\mathrm{Fe}^{2+}
$$

$\mathrm{Ni}$ obtained by displacement reaction would load on Fe surface area [19]. In addition, starch-sodium citrate-nZVI (SS-nZVI) was prepared by adding starch and sodium carboxymethyl cellulose into $100 \mathrm{ml}$ $0.5 \mathrm{M} \mathrm{FeSO}$ aqueous solution. Then $\mathrm{NaBH}_{4}$ aqueous solution was subtly added with mixing 30 min under $\mathrm{N}_{2}$ protection. Starch-Sodium carboxymethyl cellulosenZVI-Ni (SS-nZVI-Ni) was prepared by adding SS-nZVI into $0.3 \mathrm{M} \mathrm{NiCl}_{2}$ aqueous solution with mixing 20 min under $\mathrm{N}_{2}$ protection.

\section{Characterizations}

To figure out the differences between SS-nZVI$\mathrm{Ni}$ and those after reaction with Cr (VI), XRD (X'Pert Pro) and XPS (ESCALAB250Xi) were used to detect the composition of SS-nZVI-Ni surface elements. Scanning electron microscope (SEM) images were obtained with / Nova 400 NanoSEM for surface feature observation.

\section{Cr(VI) Removal Experiments}

Cr(VI) removal by two multiple modified nZVIs and original nZVI (SS-nZVI, SS-nZVI-Ni and nZVI) were examined by adding the adsorbent $(1 \mathrm{~g})$ into $100 \mathrm{~mL} \mathrm{Cr}(\mathrm{VI})$ solutions $(1 \mathrm{mg} / \mathrm{L})$ at room temperature $\left(25 \pm 2^{\circ} \mathrm{C}\right)$. After that, the capped conical flasks were shaken at $150 \mathrm{rpm}$ in a constant temperature shaker. $1 \mathrm{~mL}$ of solution sample was withdrawn and filtered through a $0.45 \mu \mathrm{m}$ membrane at selected time intervals for analysis of the concentration of $\mathrm{Cr}(\mathrm{VI})$ by the 1,5-diphenylcarbazide method, with an ultravioletvisible UV-6100S double beam spectrophotometer at $\lambda=540 \mathrm{~nm}$. 
The effects of different solution $\mathrm{pH}$ and initial $\mathrm{Cr}(\mathrm{VI})$ concentration on $\mathrm{Cr}(\mathrm{VI})$ removal were also examined. The effect of $\mathrm{pH}$ was studied by adjusting initial $\mathrm{pH}$ from 2 to 7 using $0.05 \mathrm{M} \mathrm{H}_{2} \mathrm{SO}_{4}$. The effect of initial $\mathrm{Cr}(\mathrm{VI})$ concentration was studied at the $\mathrm{Cr}(\mathrm{VI})$ concentrations varying from 0.2 to $1 \mathrm{mg} / \mathrm{L}$. Within a predetermined time, $0.05 \mathrm{~g}$ of modified nZVI was added into this simulated contaminated liquid.

The rate of SS-nZVI-Ni for Cr(VI) reduction was obtained by the following formula:

$$
R(\%)=\frac{C_{0} \quad C_{1}}{C_{0}} \times 100 \%
$$

...where $\mathrm{R}(\%)$ is the reduction rate of SS-nZVI-Ni for $\mathrm{Cr}(\mathrm{VI}), \mathrm{C}_{0}$ is the initial $\mathrm{Cr}(\mathrm{VI})$ concentration, and $\mathrm{C}_{1}$ is the concentration of $\mathrm{Cr}(\mathrm{VI})$ at a predetermined time.

\section{Results and Discussion}

\section{Characterization of SS-nZVI-Ni}

In order to study the mechanism of $\mathrm{Cr}(\mathrm{VI})$ removal by SS-nZVI-Ni, XPS and XRD analyses were performed to measure the chemical compositions on the surface. The XPS spectra confirmed that the prepared SS-nZVI$\mathrm{Ni}$ contained the elements $\mathrm{Fe}, \mathrm{C}, \mathrm{O}$, and $\mathrm{Ni}$, which indicated that both starch and sodium citrate wrapped on the surface of nZVI and Ni was loaded on the nZVI. $\mathrm{Cr}$ can be observed in the survey of SS-nZVI-Ni after reaction with $\mathrm{Cr}(\mathrm{VI})$ (Fig. 1a). The $\mathrm{Cr} 2 \mathrm{p}$ spectra after the reaction have two peaks - at $586.3 \mathrm{eV}\left(\mathrm{Cr} 2 \mathrm{p}_{1 / 2}\right)$ and 576.2 $\mathrm{eV}\left(\mathrm{Cr} 2 \mathrm{p}_{3 / 2}\right)$ (Fig. 1b). The binding energy at $576.2 \mathrm{eV}$ conforms to $\mathrm{Cr}_{2} \mathrm{O}_{3}$, and the binding energy at $586.3 \mathrm{eV}$ corresponds to $\mathrm{Cr}$ oxides, which indicates that $\mathrm{Cr}_{2} \mathrm{O}_{3}$ precipitate was formed during the adsorption and the reduction of $\mathrm{Cr}$ (VI) [20].

In the Fe2p XPS spectrum, the peak at $710.2 \mathrm{eV}$ binding energy correspond to $\mathrm{Fe} 2 \mathrm{p}_{3 / 2}$ of $\mathrm{Fe}_{3} \mathrm{O}_{4}$ or $\mathrm{FeO}$, while the peak at $724.6 \mathrm{eV}$ binding energy correspond to $\mathrm{Fe} 2 \mathrm{p}_{1 / 2}$, which confirms the existence of elemental Fe. After the reaction, the percentages of $\mathrm{Fe}$ and $\mathrm{Ni}$ atoms in SS-nZVI-Ni decreased from $19.05 \%$ to $18.89-3.19 \%$ to $2.92 \%$. In contrast, the percentages of $\mathrm{C}$ and $\mathrm{Cr}$ atoms increased from $23.18 \%$ to $25.10-0 \%$ to $0.79 \%$. Therefore, the $\mathrm{C} / \mathrm{O}$ ratio in SS-nZVI-Ni increased from 0.425 to 0.480 after reaction with $\mathrm{Cr}(\mathrm{VI})$. And these result implied that iron oxides and $\mathrm{Ni}$ had participated in the adsorption and reduction of $\mathrm{Cr}(\mathrm{VI})$.

The XRD patterns of SS-nZVI-Ni before reaction with $\mathrm{Cr}(\mathrm{VI})$ showed a peak of $\mathrm{Fe}$ and $\mathrm{Ni}$ alloy $\left(2 \theta=44.76^{\circ}\right)$, which decreased dramatically after the reaction. The XRD patterns of SS-nZVI-Ni after reaction with $\mathrm{Cr}(\mathrm{VI})$ indicated the appearance of $\mathrm{Fe}_{99} \mathrm{Fe}_{1.97} \mathrm{Cr}_{.03} \mathrm{Ni}_{.01} \mathrm{O}_{4}\left(2 \theta=35.43^{\circ}\right)$ and $\mathrm{Fe}_{3} \mathrm{O}_{4}\left(2 \theta=35.44^{\circ}\right)$, which were not detected before the reaction [10, 21]. After reaction, $\mathrm{Cr}$ (III) was found in an oxide consisting of $\mathrm{Ni}, \mathrm{Cr}, \mathrm{Fe}$, and $\mathrm{O}$, which demonstrated that SS-nZVI-Ni had participated in Cr (VI) redox reaction. Thus from the result in Fig. 2, Cr(VI) in initial solutions was reduced to an alloy containing $\mathrm{Cr}$ (III), which was

a)
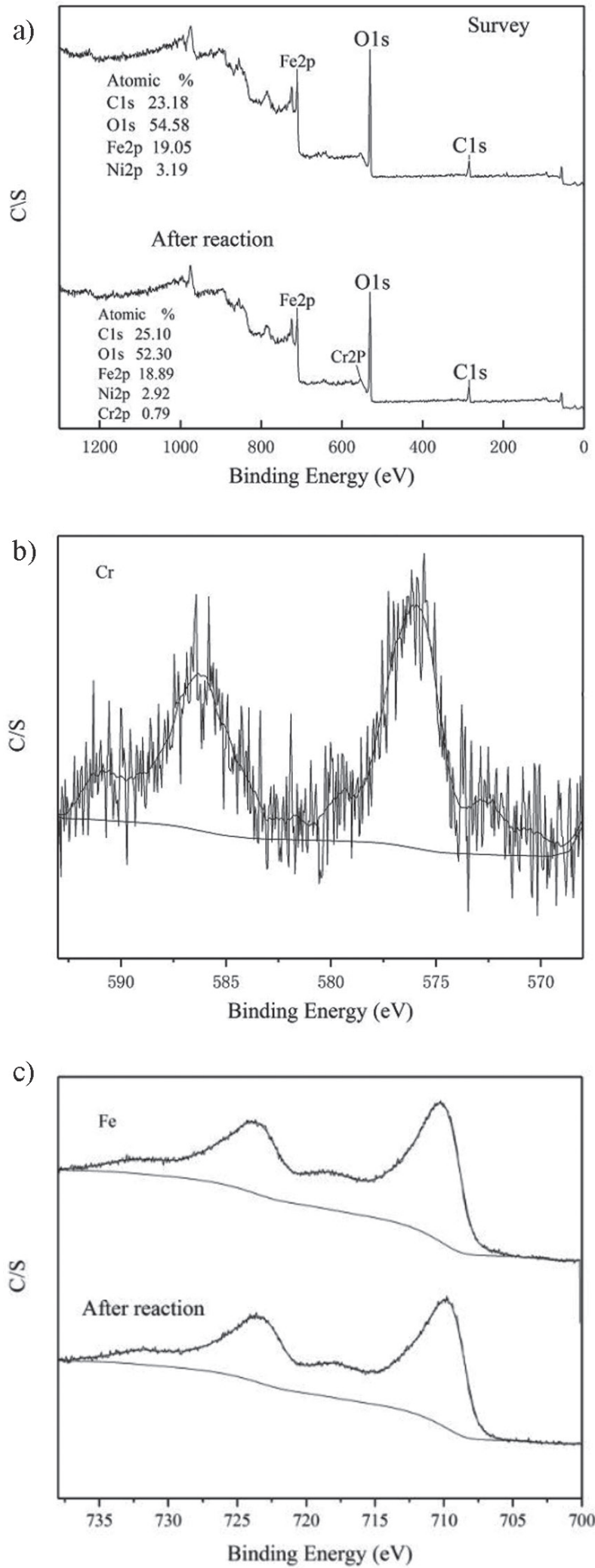

Fig. 1. XPS patterns; a) XPS spectra; b) XPS spectra for $\mathrm{Cr} 2 \mathrm{p}$ in SS-nZVI-Ni; c) XPS spectra for Fe 2p in SS-nZVI-Ni. 


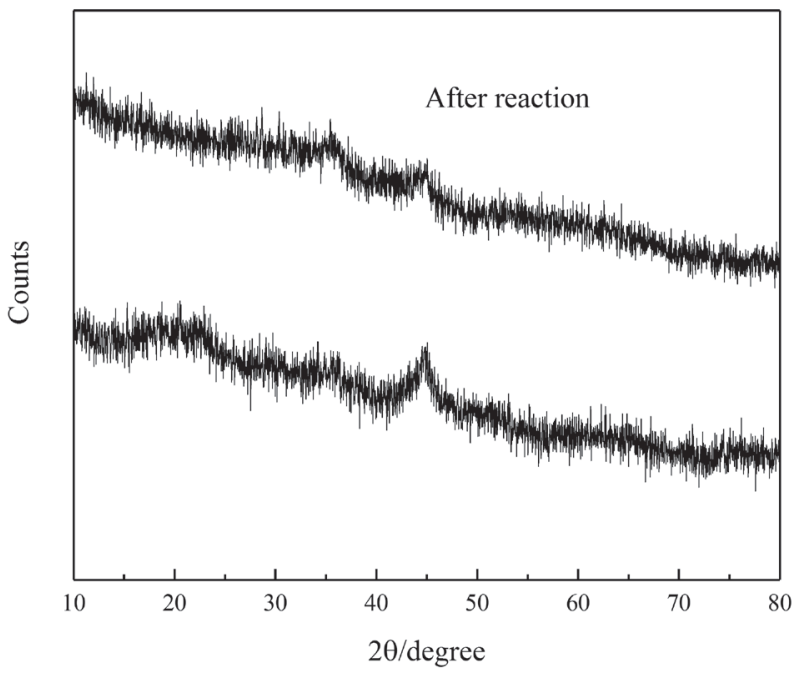

Fig. 2. XRD patterns of SS-nZVI-Ni.

immobilized on the surface of SS-nZVI-Ni. And for iron particles, nZVI was oxidized to $\mathrm{Fe}_{3} \mathrm{O}_{4}$ and an alloy containing $\mathrm{Fe}(\mathrm{II})$ and $\mathrm{Fe}(\mathrm{III})$.

To further investigate the removal mechanism, the microstructural features of SS-nZVI-Ni before and after reaction with $\mathrm{Cr}(\mathrm{VI})$ were analyzed by SEM (Figs 3a and 3c, respectively), SS-nZVI-Ni existed in the form of a sphere, with sizes ranging from $100 \sim 150 \mathrm{~nm}$. NZVI-Gr coated by starch [13], nZVI supported by pumice [22], and nZVI supported by activated carbon [23] gained similar results. While after reaction, the SEM images showed that SS-nZVI-Ni particles become larger, with sizes

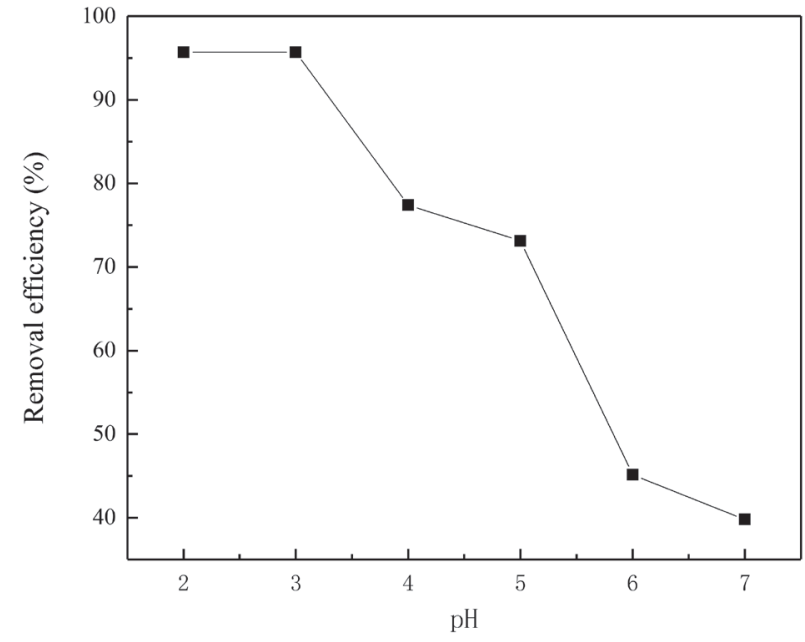

Fig. 4. Effect of $\mathrm{pH}$ on $\mathrm{Cr}(\mathrm{VI})$ removal of SS-nZVI-Ni.

ranging from $200 \sim 250 \mathrm{~nm}$. Before the reaction, there is a relatively wide gap between the particles, which could make $\mathrm{Cr}(\mathrm{VI})$ be adsorbed on SS-nZVI-Ni surface. And after the reaction, the gap between the particles narrowed due to the adsorption and reduction of $\mathrm{Cr}(\mathrm{VI})$, an alloy containing $\mathrm{Cr}$ formed on the surface of SS-nZVI-Ni.

\section{Effect of $\mathrm{pH}$ on $\mathrm{Cr}$ (VI) Removal by SS-nZVI-Ni}

Fig. 4 shows that with the increase in $\mathrm{pH}$, the removal rate of $\mathrm{Cr}(\mathrm{VI})$ in one hour decreased rapidly. Especially when the $\mathrm{pH}$ reached 7 did the removal rate sink to $39.78 \%$. These results demonstrated that

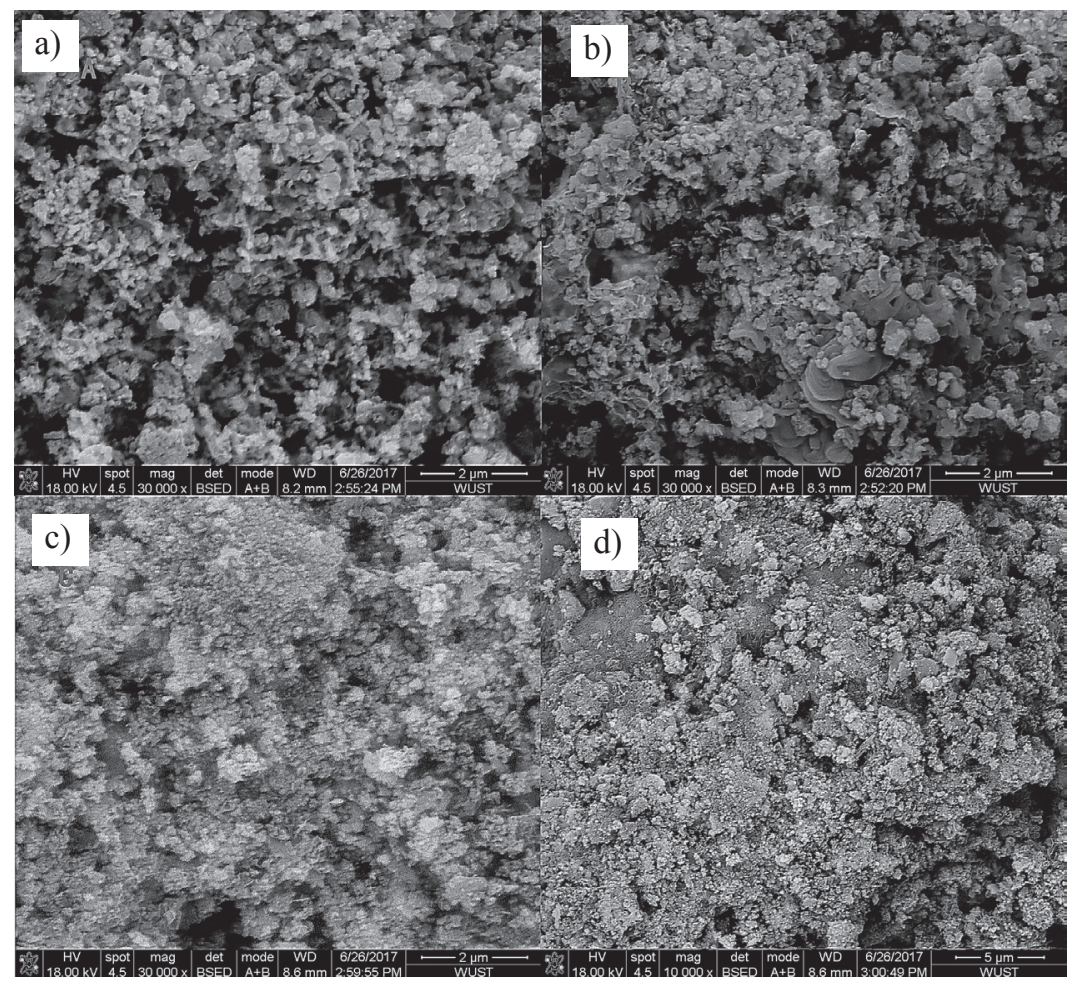

Fig. 3. SEM images of SS-nZVI-Ni; a,b) SEM images of SS-nZVI-Ni before reaction; c,d) SEM images of SS-nZVI-Ni after reaction. 
the lower the $\mathrm{pH}$, the more obvious the removal effect. In the range of $\mathrm{pH}$ from 2 to $7, \mathrm{Cr}(\mathrm{VI})$ mainly exists in tow forms, $\mathrm{HCrO}-4$ (between $\mathrm{pH}$ from 2 to 6) and $\mathrm{CrO}_{2}$ - 4(above $\mathrm{pH}$ 6). The following redox reaction is promoted due to the strong acid environment generated by $\mathrm{H}^{+}[24]$.

$$
\begin{gathered}
\mathrm{HCrO}_{4}^{-}+7 \mathrm{H}^{+}+\mathrm{Fe}^{0} \rightarrow \mathrm{Fe}^{3+}+\mathrm{Cr}^{3+}+4 \mathrm{H}_{2} \mathrm{O} \\
\mathrm{CrO}_{4}^{2-}+\mathrm{Fe}^{0}+8 \mathrm{H}^{+} \rightarrow \mathrm{Cr}^{3+}+\mathrm{Fe}^{3+}+4 \mathrm{H}_{2} \mathrm{O} \\
2 \mathrm{HCrO}_{4}^{-}+14 \mathrm{H}^{+}+3 \mathrm{Ni} \rightarrow 3 \mathrm{Ni}^{2+}+2 \mathrm{Cr}^{3+}+8 \mathrm{H}_{2} \mathrm{O} \\
2 \mathrm{CrO}_{4}^{2-}+16 \mathrm{H}^{+}+3 \mathrm{Ni} \rightarrow 3 \mathrm{Ni}^{2+}+2 \mathrm{Cr}^{3+}+8 \mathrm{H}_{2} \mathrm{O}
\end{gathered}
$$

From the previous analysis of the XPS spectra, $\mathrm{Cr}(\mathrm{VI})$ removed by SS-nZVI-Ni contains adsorption and reduction [20]. In the beginning of the reaction, $\mathrm{Cr}(\mathrm{VI})$ ions were adsorbed onto the SS-nZVI-Ni surface, and reduced to $\mathrm{Cr}$ (III) by ZVI and Ni (Eqs 1-4). Subsequently, $\mathrm{Cr}$ (III), Fe(II), Fe(III), and Ni(II) oxides formed an alloy. $\mathrm{Cr}$ (III) would precipitate out of the alloy and then from the water $[25,26]$. From those equations, we can prove that $\mathrm{H}^{+}$plays an important role in the whole reaction. The increasing of $\mathrm{H}^{+}$can shift the reaction equilibrium toward the positive side and can explain that lower $\mathrm{pH}$ is advantageous to the removal of $\mathrm{Cr}(\mathrm{VI})$. At lower $\mathrm{pH}$, the corrosion of $\mathrm{ZVI}$ and $\mathrm{Ni}$ accelerated. ZVI was corroded by $\mathrm{H}^{+}$into $\mathrm{Fe}^{2+}$, which resulted in $\mathrm{Fe}^{2+}$ continuing to participate in the reaction. Therefore, an acidic environment promoted the reaction between $\mathrm{Cr}(\mathrm{VI})$ and $\mathrm{Fe}$ [27]. In this study, $\mathrm{pH}$ was also recorded when the predetermined time was reached. The result showed that the initial $\mathrm{pH} \mathrm{5,7}$ varied to 5.6, 7.6, respectively. The increase in $\mathrm{pH}$ at the initial $\mathrm{pH} 5$ further

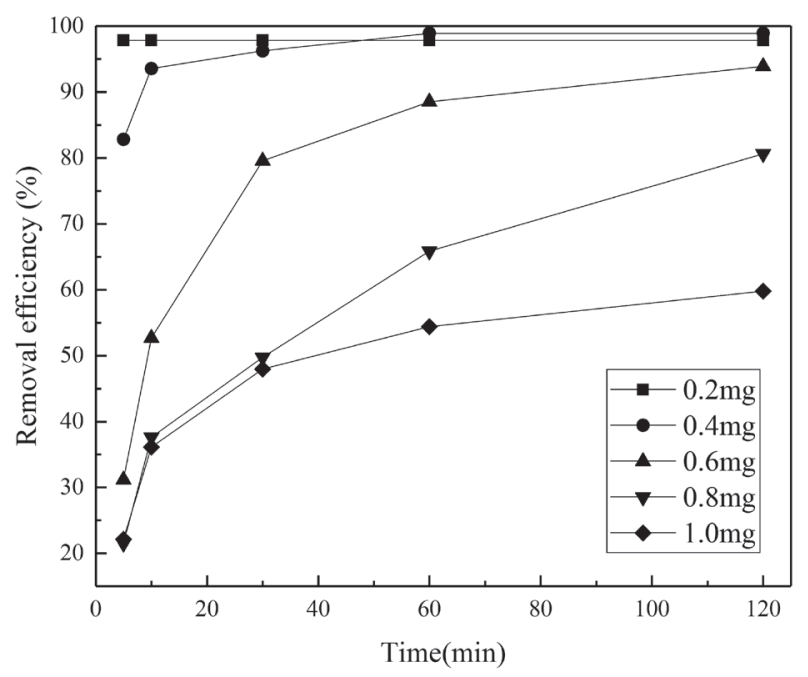

Fig. 5. Effect of different initial Cr (VI) concentration removed by SS-nZVI-Ni versus time. confirms the higher degree of ZVI corrosion under an acidic environment.

\section{The Effect of Different Initial Cr(VI) Concentrations}

To investigate the effect of different initial $\mathrm{Cr}(\mathrm{VI})$ concentrations on SS-nZVI-Ni removal efficiency, 0.2-1 $\mathrm{mg} / \mathrm{L} \mathrm{Cr}(\mathrm{VI})$ were prepared. It is shown in Fig. 5 that with the increase in concentration, reduction efficiency decreased. At an initial $\mathrm{Cr}(\mathrm{VI})$ concentration of 0.2 , within 5 min the reduction rate reached $97 \%$, and as time went by, the growth of reduction rate was not distinct. At an initial $\mathrm{Cr}(\mathrm{VI})$ concentration of $0.6 \mathrm{mg} / \mathrm{L}$ and $0.8 \mathrm{mg} / \mathrm{L}$, the average reaction rate of $\mathrm{Cr}(\mathrm{VI})$ decreased from $0.1591 \mathrm{mg} / \mathrm{min}$ to $0.1326 \mathrm{mg} / \mathrm{min}$, and the next $90 \mathrm{~min}$. the removal rate grew steadily over time. In general, as the initial $\mathrm{Cr}$ (VI) concentration increased, the final removal rate decreased. Because $\mathrm{Cr}(\mathrm{VI})$ is a strong oxidant, when high $\mathrm{Cr}(\mathrm{VI})$ concentration contacted with $\mathrm{nZVI}$ and $\mathrm{Ni}$, both $\mathrm{nZVI}$ and $\mathrm{Ni}$ could be oxidized and lost their power of reducing in a moment. And XRD patterns demonstrated that $\mathrm{nZVI}, \mathrm{Ni}$, and $\mathrm{Cr}$ (III) formed an alloy that attached to the surface of SS-nZVI-Ni. In this way, the precipitated product could slow down the further contact of nZVI and $\mathrm{Cr}(\mathrm{VI})$. Lu used MCM-41 to stabilize nZVI for $\mathrm{Cr}(\mathrm{VI})$ removal [28] illustrating that it was the formation of precipitated product that slows down the reaction. And $\mathrm{Fu}$ [29] gains similar results. Thus, nZVI that was modified by multiple matters plays a promoting role in keeping the reactivity of nZVI.

\section{The Effects of Different Modifiers Coating nZVI}

nZVI were modified by multiple organic materials and $\mathrm{Ni}$, which were used for $\mathrm{Cr}(\mathrm{VI})$ removal. Fig. 6 shows the good performance of SS-nZVI-Ni and SS-nZVI. Obviously, in the first $5 \mathrm{~min}$. of the

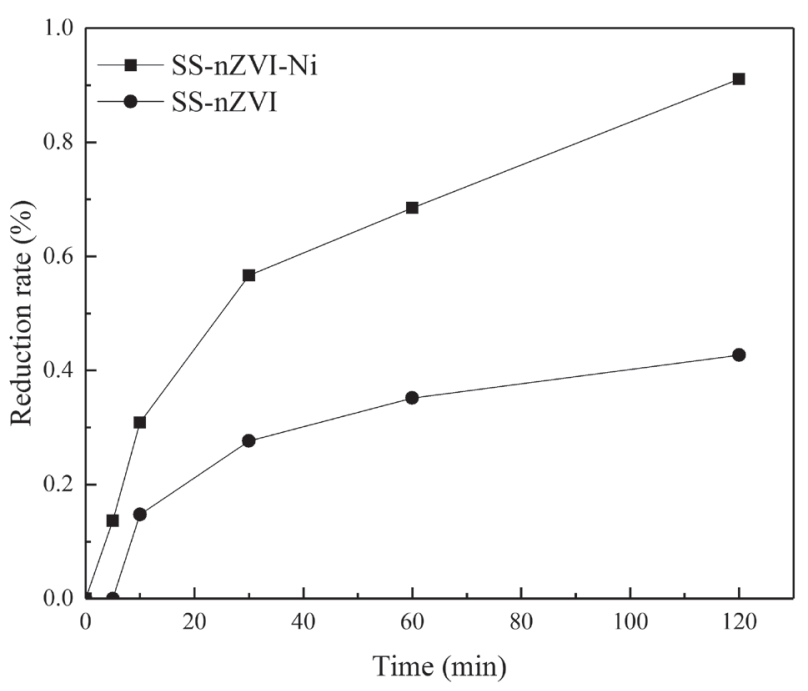

Fig. 6. Effect of different modifier coating nZVI. 
experiment, SS-nZVI-Ni removes faster than SS-nZVI in the rate of removal of $\mathrm{Cr}(\mathrm{VI})$, it achieves $13.66 \%$. After $60 \mathrm{~min}$, the removal rate of SS-nZVI increases slowly over time, and meanwhile the removal rate of SS-nZVI-Ni can barely see the trend of slowing down. In 120 min., the removal rate of SS-nZVI-Ni reaches $91.08 \%$, which is twice the rate of SS-nZVI. The SEM image indicates that SS-nZVI-Ni has a large surface area. And the XRD patterns show Ni loaded in nZVI participated in reaction. $\mathrm{Ni}$ also was used as a reducing agent to reduce $\mathrm{Cr}(\mathrm{VI})$ to $\mathrm{Cr}(\mathrm{III})$. Moreover, Ni also formed an alloy with $\mathrm{Cr}$ (III) on the surface of nZVI. All these Ni features make SS-nZVI-Ni more efficient than SS-nZVI. Kumarathilaka [13] proved that nZVI-Gn coated by starch would provide more efficient removal effect than nZVI modified by graphene composite. Chen [30] proved that nZVI modified by different and single material such as starch and sodium carboxymethyl cellulose gained a better removal rate than nZVI. And at the same time and interval and environmental impact factors, SS-nZVI-Ni the final removal rate is better than these single or double modified nZVI. This would mean that multiple modifiers of nZVI could result in higher $\mathrm{Cr}(\mathrm{VI})$ removal efficiency.

\section{The Study of Kinetics}

The reaction between SS-nZVI-Ni and Cr (VI) is associated with the multiphase surface reaction. To investigate the reduction mechanism, $\mathrm{Zhu}$ [27] used the Langmuir-Hinshelwood first-order kinetic model to evaluate the reaction kinetics:

$$
\mathrm{v}=-\frac{\mathrm{d} C}{d t}=\frac{K b C}{1+b C}
$$

...where K represents the reaction rate constant of a solid surface and $\mathrm{b}$ is a constant associated with adsorption heat and temperature. When the reaction substrate concentration is very low, bC«1 and formula (7) can be written as:

$$
\mathrm{v}=-\frac{\mathrm{dC}}{d t}=K b C=k_{o b s} C
$$

When $\mathrm{k}_{\mathrm{obs}}$ is equal to $\mathrm{Kb}$ in Equation (8), the reaction can be simplified as a first-order reaction model being integrated into Equation (9):

$$
\ln \left(C_{t} / C_{0}\right)=-k_{o b s} t+c
$$

...where $\mathrm{C}_{t}$ is the concentration of $\mathrm{Cr}(\mathrm{VI})$ at $\mathrm{t}$ min., $\mathrm{C}_{0}$ is the initial $\mathrm{Cr}(\mathrm{Vi})$ concentration, c represents a constant, and $\mathrm{k}_{\text {obs }}$ is the apparent rate constant $\left(\mathrm{min}^{-1}\right)$, calculated from the line plot slope between $\ln \left(\mathrm{C}_{\mathrm{t}} / \mathrm{C}_{0}\right)$ versus t.

The half-life $t_{1 / 2}$ is defined as the time at which half of the initial hexavalent chromium pollutants are degraded completely, which is calculated using the following equation:

$$
\mathrm{t}_{1 / 2}=\ln (2) / k_{\text {obs }}
$$

As shown in Fig. $7 \mathrm{a}), \ln \left(\mathrm{C}_{\mathrm{t}} / \mathrm{C}_{0}\right)$ had a good linear correlation with reaction time $\mathrm{t}$, suggesting that the reduction process of $\mathrm{Cr}(\mathrm{VI})$ followed the LangmuirHinshelwood first-order kinetic in different multiple modifier. SS-nZVI-Ni and SS-nZVI $\mathrm{k}_{\text {obs }}$ were 0.0188 and $0.0043 \mathrm{~min}^{-1}$, respectively. Two nZVI were evidently different. SS-nZVI-Ni was obviously better than SSnZVI in $\mathrm{Cr}(\mathrm{VI})$ removal. This meant multiple modifiers were helpful for nZVI in $\mathrm{Cr}(\mathrm{VI})$ removal. The halflife periods were 36.87 and $161.2 \mathrm{~h}$ between SS-nZVI$\mathrm{Ni}$ and SS-nZVI, respectively. NZVI modified by more modifiers led to larger surface area, which increased the rate of $\mathrm{Cr}(\mathrm{VI})$ removal. a)

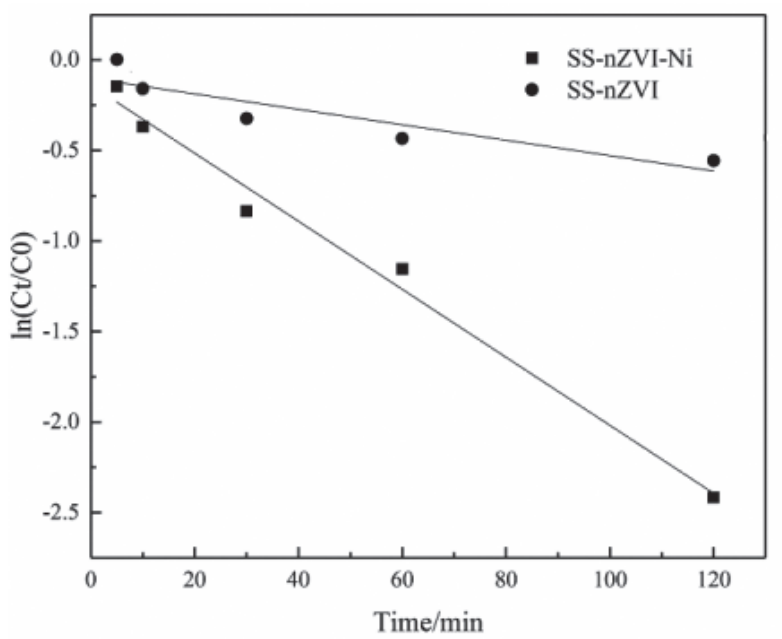

b)

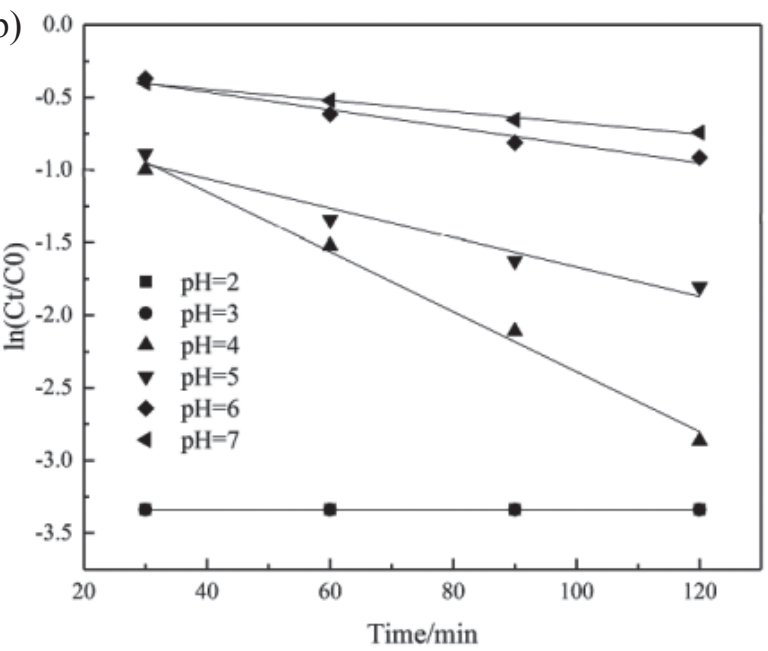

Fig. 7. Langumir-Hinshelwood first order kinetic model of SS-nZVI-Ni. 
The Langmuir-Hinshelwood first-order kinetic model was applied to analyze the effect of $\mathrm{pH}$ on $\mathrm{Cr}(\mathrm{VI})$ reduction. Fig. $7 \mathrm{~b}$ ) showed that when $\mathrm{pH}$ values were $4,5,6$, and $7, \mathrm{k}_{\text {obs }}$ were $0.0206,0.0101,0.0061$, and $0.0039 \mathrm{~min}^{-1}$, respectively. The apparent rate constants $\mathrm{k}_{\mathrm{obs}}$ decreased at the $\mathrm{pH}$ increase, which showed that acidic condition was beneficial to $\mathrm{Cr}$ (VI ) removal by SS-nZVI-Ni. And the half-life periods were 33.65, 68.63, 113.6, and $177.7 \mathrm{~h}$, respectively. This illustrated that at lower $\mathrm{pH}$, SS-nZVI-Ni would reach maximum removal efficiency.

\section{Conclusions and Implications}

In this study, the feasibility of nZVI modified by multiple modifiers (starch sodium carboxymethyl cellulose and $\mathrm{Ni}$ ) for $\mathrm{Cr}(\mathrm{VI})$ removal was investigated. The result proved that SS-nZVI-Ni was an effective and promising composite for $\mathrm{Cr}$ (VI) removal. The performance of SS-nZVI-Ni was highly $\mathrm{pH}$ dependent, and at $\mathrm{pH}=2$ the maximum $\mathrm{Cr}(\mathrm{VI})$ removal efficiency was observed. The performance of different multiples suggested that the removal efficiency of SS-nZVI-Ni on $\mathrm{Cr}(\mathrm{VI})$ removal surpassed SS-nZVI. And at higher $\mathrm{Cr}(\mathrm{VI})$ concentrations, the removal efficiency of SSnZVI-Ni could decline less. Meanwhile SEM images revealed that SS-nZVI-Ni was capable of a larger surface area, which solved the problem of aggregation. XRD and XPS confirmed that SS-nZVI-Ni had participated in adsorption and reduction of Cr(VI). Thus, SS-nZVI$\mathrm{Ni}$ proved to be an effective environmentally friendly reagent for treating $\mathrm{Cr}(\mathrm{VI})$ in groundwater.

\section{Acknowledgements}

This research was financially supported by a project (2017zy011) of Hubei Key Laboratory for Efficient Utilization and Agglomeration of Metallurgic Mineral Resources, a project (2017C003) of Hubei Key Laboratory of Regional Development and Environmental Response (Hubei University), Scientific Research Project for University Student of WUST (16ZRA022, 16ZRA023), and the Natural Science Foundation of Hubei Province of China (2017CFB350).

\section{References}

1. SIGEL A., SIGEL H. Metal Ions in Biological Systems, Volume 35: Iron Transport and Storage Microorganisms, Plants, and Animals, Metal-Based Drugs, 5, 262, 1998.

2. BISWAS P., KARN A.K., KALE P.G., BALASUBRAMANIAN P. Biosensor for detection of dissolved chromium in potable water: A review, BIOSENS BIOELECTRON, 94, 589, 2017.

3. SÁNCHEZ J., BUTTER B., BASÁEZ L., RIVAS B.L., THOTIY M.O. Efficient removal of $\mathrm{Cr}(\mathrm{VI})$ BY
Polyelectrolyte-assisted ultrafiltration and subsequent electrochemical reduction to $\mathrm{Cr}(\mathrm{III})$, J CHIL CHEM SOC, 62, 3647, 2017.

4. LIU Q., XU M., LI F., WU T., LI Y. Rapid and effective removal of $\mathrm{Cr}(\mathrm{VI})$ from aqueous solutions using the $\mathrm{FeCl} 3$ /NaBH 4 system, CHEM ENG J, 296, 340, 2016.

5. HABILA M., UNSAL Y.E., ALOTHMAN Z.A., SHABAKA A., TUZEN M., SOYLAK M. Speciation of Chromium in Natural Waters, Tea, and Soil with Membrane Filtration Flame Atomic Absorption Spectrometry, ANAL LETT, 48, 2258, 2015.

6. KARTHIK R., MEENAKSHI S. Removal of $\mathrm{Cr}(\mathrm{VI})$ ions by adsorption onto sodium alginate-polyaniline nanofibers, INT J BIOL MACROMOL, 72, 711, 2015.

7. AND C.B.W., ZHANG W. Synthesizing Nanoscale Iron Particles for Rapid and Complete Dechlorination of TCE and PCBs, Environmental Science Technology, 31, 9602, 1997.

8. CHRYSOCHOOU M., REEVES K. Reduction of Hexavalent Chromium by Green Tea Polyphenols and Green Tea Nano Zero-Valent Iron (GT-nZVI)., Bulletin of Environmental Contamination \& Toxicology, 1, 2016.

9. XIAO Z., ZHANG H., XU Y., YUAN M., JING X., HUANG J., LI Q., SUN D. Ultra-efficient removal of chromium from aqueous medium by biogenic iron based nanoparticles, Separation \& Purification Technology, 174, 466, 2016.

10. DONG H., DENG J., XIE Y., CONG Z., ZHAO J., CHENG Y., HOU K., ZENG G. Stabilization of nanoscale zerovalent iron (nZVI) with modified biochar for $\mathrm{Cr}(\mathrm{VI})$ removal from aqueous solution, J HAZARD MATER, 332, 79, 2017.

11. GAO J.F., LI H.Y., PAN K.L., SI C.Y. Green synthesis of nanoscale zero-valent iron using a grape seed extract as a stabilizing agent and the application for quick decolorization of azo and anthraquinone dyes, RSC ADV, 6, 22526, 2016.

12. EZZATAHMADI N., AYOKO G.A., MILLAR G.J., SPEIGHT R., YAN C., LI J., S. LI, ZHU J., XI Y. Clay-supported nanoscale zero-valent iron composite materials for the remediation of contaminated aqueous solutions: A Review, 2016.

13. KUMARATHILAKA P., JAYAWEERA V., WIJESEKARA H., KOTTEGODA I.R.M., ROSA S.R.D., VITHANAGE M. Insights into Starch Coated Nanozero Valent Iron-Graphene Composite for CrVI Removal from Aqueous Medium, J NANOMATER, 2016, 7, 2016.

14. TSO C.P., SHIH Y.H. The influence of carboxymethylcellulose (CMC) on the reactivity of Fe NPs toward decabrominated diphenyl ether: The Ni doping, temperature, $\mathrm{pH}$, and anion effects, J HAZARD MATER, 322, 145, 2016.

15. WANG H., ZOU Z., XIAO X., CHEN D., YANG K. Reduction of highly concentrated phosphate from aqueous solution using pectin-nanoscale zerovalent iron (PNZVI), Water Science \& Technology A Journal of the International Association on Water Pollution Research, 73, 2689, 2016.

16. SOLIEMANZADEH A., FEKRI M. The application of green tea extract to prepare bentonite-supported nanoscale zero-valent iron and its performance on removal of $\mathrm{Cr}(\mathrm{VI})$ : Effect of relative parameters and soil experiments, Microporous \& Mesoporous Materials, 239, 60, 2017.

17. NIKSEFAT M., AYATI B. Reduction and reuse of Fe-Ni bimetallic nanoparticles oxide and evaluating its ability in acid red 14 removal, ENVIRON PROG SUSTAIN, 35, 1646, 2016. 
18. LIY., LI X., HAN D., HUANG W., YANG C. New insights into the role of Ni loading on the surface structure and the reactivity of nZVI toward tetrabromo- and tetrachlorobisphenol A, CHEM ENG J, 311, 173, 2017.

19. YING L., LI X., YANG X., WEI C., HAN D., HUANG W. Catalytic debromination of tetrabromobisphenol A by Ni/nZVI bimetallic particles, CHEM ENG J, 284, 1242, 2016.

20. TIAN X., WANG W., NA T., ZHOU C., CHAO Y., KOMARNENI S. Cr(VI) reduction and immobilization by novel carbonaceous modified magnetic $\mathrm{Fe}_{3} \mathrm{O}_{4}$ /halloysite nanohybrid, J HAZARD MATER, 309, 151, 2016.

21. LI Y., LI J., ZHANG Y. Mechanism insights into enhanced $\mathrm{Cr}(\mathrm{VI})$ removal using nanoscale zerovalent iron supported on the pillared bentonite by macroscopic and spectroscopic studies, J HAZARD MATER, 211-218, 227, 2012.

22. HARMAN B.I., GENISOGLU M. Synthesis and Characterization of Pumice-Supported nZVI for Removal of Copper from Waters, Advances in Materials Science and Engineering, (2016-4-21), 2016(2016) 1-10, 2016.

23. CHEN W.F., ZHANG J., ZHANG X., WANG W., LI Y. Investigation of heavy metal $(\mathrm{Cu}, \mathrm{Pb}, \mathrm{Cd}$, and $\mathrm{Cr})$ stabilization in river sediment by nano-zero-valent iron/ activated carbon composite., Environmental Science \& Pollution Research, 23, 1460, 2015.

24. SOLIEMANZADEH A., FEKRI M. The application of green tea extract to prepare bentonite-supported nanoscale zero-valent iron and its performance on removal of
$\mathrm{Cr}(\mathrm{VI})$ : Effect of relative parameters and soil experiments, Microporous \& Mesoporous Materials, 239, 60, 2017.

25. CHEN S.S., CHENG C.Y., LI C.W., CHAI P.H., CHANG Y.M. Reduction of chromate from electroplating wastewater from $\mathrm{pH} 1$ to 2 using fluidized zero valent iron process, J HAZARD MATER, 142, 362, 2007.

26. MUCHA N.R., RAVELLA R., REDDY M.R., ZHANG L. Electrospun Carbon Nanofiber Supported Zero Valent Iron Nanoparticles (nZVI@ECNFs) for Cr (VI) Remediation in Ground and Waste Water, Mrs Advances, 1, 2016.

27. FANG Z., LI L., REN W., DENG X., TAO L. Effect of pH, temperature, humic acid and coexisting anions on reduction of $\mathrm{Cr}(\mathrm{VI})$ in the soil leachate by nZVI/Ni bimetal material, ENVIRON POLLUT, 227, 444, 2017.

28. LU M., CHENG Y., PAN J.M., FAN W.J., JIAO C., LIU X.Y. Synthesis of MCM-41 stabilized NZVI and its use in removal of $\mathrm{Cr}(\mathrm{VI})$ from aqueous solution, Journal of Water Reuse \& Desalination, 5, 149, 2015.

29. RONGBING F., YINGPIN Y., ZHEN X., XIAN Z., XIAOPIN G., DONGSU B. The removal of chromium (VI) and lead (II) from groundwater using sepiolite-supported nanoscale zero-valent iron (S-NZVI), CHEMOSPHERE, 138, 726, 2015.

30. CHEN W., WANG X., YUAN Z. Preparation of nanoscale zero-valent iron particles with different coatings for removal of $\mathrm{Cr}(\mathrm{VI})$ from water, INT J Nanotechnol, 13, 923, 2016. 